\title{
PETROGLIFOS EN EL VALLE CALCHAQUÍ NORTE (SALTA, ARGENTINA): CAMÉLIDOS, MONTAÑAS Y APROPIACIÓN INKAICA DEL PAISAJE LOCAL
}

\author{
PETROGLYPHS IN THE NORTH CALCHAQUÍ VALLEY (SALTA, ARGENTINA): \\ CAMELIDS, MOUNTAINS, AND INKAIC APPROPRIATION OF THE LOCAL \\ LANDSCAPE
}

\author{
Ivan Leibowicz ${ }^{1}$, Alejandro Ferrari ${ }^{2}$, Cristian Jacob $^{3}$ y Félix Acuto ${ }^{4}$
}

\begin{abstract}
En este trabajo presentamos una primera aproximación al sitio arqueológico denominado Rincón de las Llamas (RDL1) situado en el valle Calchaquí norte, provincia de Salta, Argentina. El sitio, localizado en la cima de una colina en la cercanía del complejo inka de Cortaderas, es un afloramiento rocoso en donde se hallaron 40 rocas grabadas con representaciones figurativas y abstractas. Relevamos el afloramiento y analizamos los motivos presentes en él desde un punto de vista compositivo, representacional y espacial, a fin de establecer su posible adscripción cultural y temporal.
\end{abstract}

Palabras claves: petroglifos, camélidos, valle Calchaquí norte, inkas.

In this paper we present a first approach to the archaeological site known as Rincón de las Llamas (RDL1) located in the North Calchaquí valley, Salta province, Argentina. The site, situated on top of a hillock near the Cortaderas Inka complex, is a rocky outcrop where we found 40 engraved rocks depicting figurative and abstract motifs. We surveyed the outcrop and analyzed the arrangement of the motifs from a compositional, representational, and spatial point of view in order to suggest their chronology and cultural identity.

Key words: Petroglyphs, camelids, North Calchaquí valley, Inkas.

Se presenta aquí un primer acercamiento al sitio denominado Rincón de las Llamas (RDL1), ubicado en el valle Calchaquí norte, provincia de

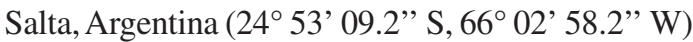
a una altura de $2.916 \mathrm{msm}$. El área en estudio se encuentra en la porción septentrional de este valle y está conformada por cadenas de cerros de baja altura y afloramientos rocosos adyacentes. En una de ellas, en la parte media de la ladera de una loma de unos $100 \mathrm{~m}$ de altura fue hallado un promontorio rocoso donde abundaban los petroglifos. Esto ocurrió como consecuencia de prospecciones sistemáticas realizadas en los alrededores del complejo inka de Cortaderas, con el fin de localizar sitios de carácter ceremonial-religioso articulados con ellos y su posible asociación con otros rasgos significativos del paisaje local. Partimos de la idea que muchos de los asentamientos e infraestructura que los inkas construyeron en el valle Calchaquí norte, así como las actividades que auspiciaban y realizaban en esta región, tuvieron por objeto incentivar y pautar la participación local en espacios y actividades ceremoniales auspiciadas por los representantes imperiales. Esto implicó, adicionalmente la apropiación y el control de adoratorios, espacios rituales y huacas (o lugares o rasgos naturales significativos y sagrados del paisaje) locales. Cabe destacar que RDL1 se encuentra ubicado a tan solo 1,6 km en línea recta del sitio inka Cortaderas Bajo y a 1,4 de Cortaderas Derecha (Figura 1).

Los bloques y los afloramientos rocosos con grabados son abundantes en la zona (Acuto et al. 2011; Díaz 1983; Gilardenghi 2010; Lanza 1996). Desde la década del sesenta, Lorandi (1966) señalaba la existencia de "campos de petroglifos"

\footnotetext{
1 Programa de Becas Postdoctorales, Instituto de Investigaciones Antropológicas, Universidad Nacional Autónoma de México, Circuito Exterior S/N, Ciudad Universitaria, CP 04510, Coyoacán, D.F., México. pinocarriaga@ hotmail.com

2 Consejo Nacional de Investigaciones Científicas y Técnicas. Instituto de Estudios Americanistas "Julián Cáceres Freyre", Universidad Austral, Buenos Aires, Argentina. alejandroferra@gmail.com

3 Facultad de Filosofía y Letras, Universidad de Buenos Aires, Buenos Aires, Argentina. zamapurro@ yahoo.com.ar

4 Instituto Multidisciplinario de Historia y Ciencias Humanas, Consejo Nacional de Investigaciones Científicas y Técnicas, Saavedra 15, Piso 5, C1083ACA, Buenos Aires, Argentina. facuto@gmail.com
} 


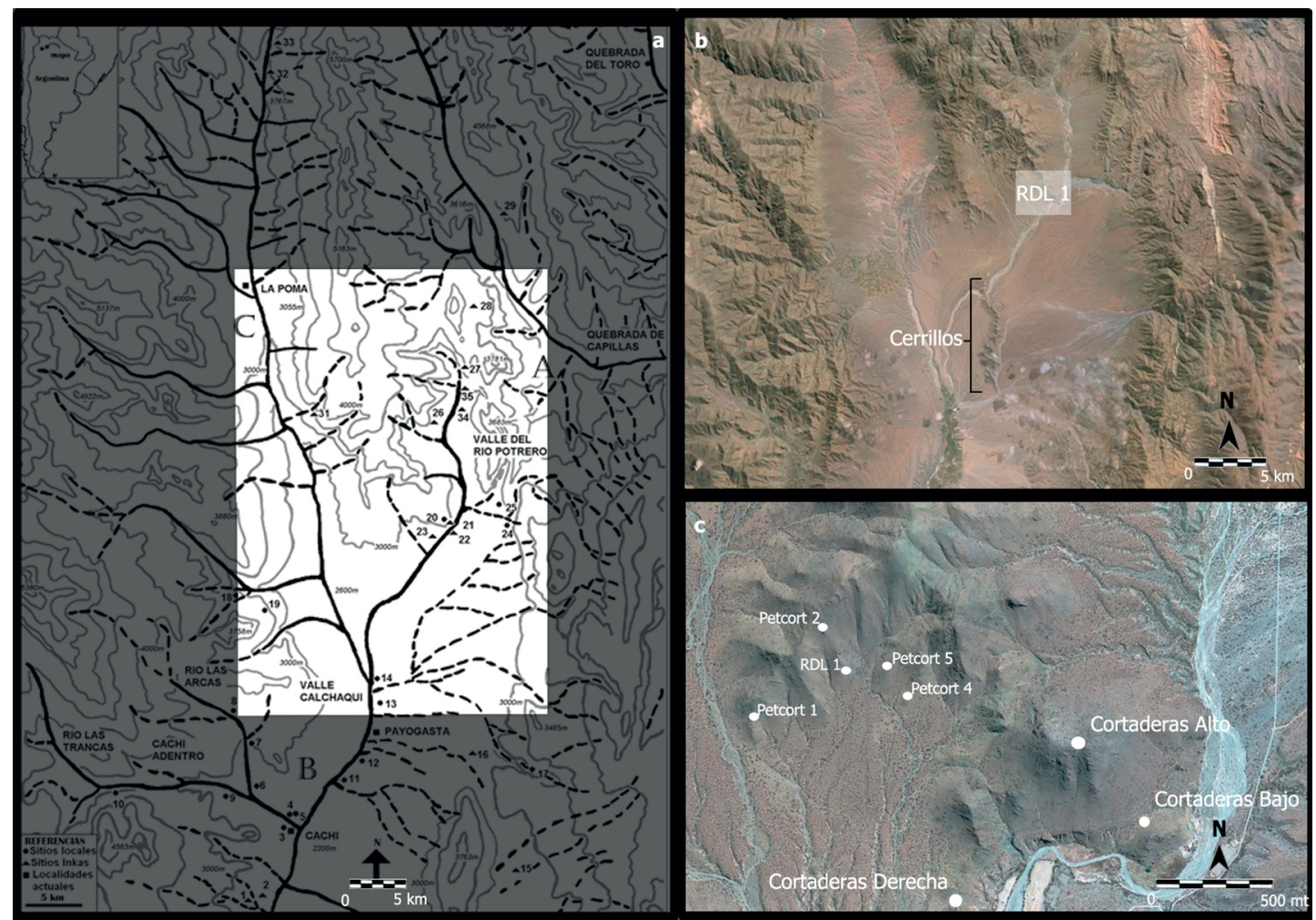

Figura 1. a. Valle Calchaquí norte destacando la zona de estudio. b. Localización de los cerros y cadenas de cerros de los que se hablará en este artículo. c. Detalle de la zona relevada y posición relativa de RDL1 respecto del complejo inka de Cortaderas. a. North Calchaquí valley, area under study highlighted. b. Location of the hills and hill ranges which will be discussed in this article. c. Detail of the surveyed area and RDL1's position in relation to the Cortaderas Inka complex.

con grandes bloques de rocas con grabados. En las cercanías de RDL1, en la misma cadena de cerros bajos, a $10 \mathrm{~km}$ de Los Cerrillos y en un radio no mayor a $450 \mathrm{~m}$, se han registrado otros cuatro promontorios rocosos con expresiones rupestres aisladas (denominados Petcort 1, Petcort 2, Petcort 4 y Petcort 5). Sin embargo, en esta área en particular (Figura 1c) RDL1 sobresale por la alta concentración de grabados en un reducido espacio de menos de $400 \mathrm{~m}^{2}$. Se han contabilizado allí 250 representaciones diseminadas a cielo abierto sobre 40 bloques pétreos. La técnica utilizada en la totalidad de los petroglifos es la de grabado por percusión o piqueteado. Los soportes se presentan como parte de afloramientos rocosos en cerros de baja altura y como rocas dispersas producto de su fragmentación. Es decir, que la roca utilizada como soporte de estas manifestaciones corresponde exclusivamente a estos afloramientos y no encontramos evidencia alguna que permita inferir que las rocas grabadas dispersas fueran transportadas desde otro lugar ${ }^{1}$.

Dado que el estudio no se ha profundizado de modo que nos permita asignar cronologías absolutas, la adscripción temporal relativa será inferida apelando a: la cantidad de representaciones y los tipos de motivos representados, su relación con otras tendencias previamente sugeridas para esta zona (con énfasis en la frecuencia relativa de las representaciones y su localización con relación a sitios de habitación), las relaciones espaciales con el paisaje circundante y los sitios cercanos, y referencias etnohistóricas. Sugeriremos finalmente que, dados los motivos representados en RDL 1, sus frecuencias relativas, su localización, topografía, y evidencias complementarias de actividades llevadas a cabo en el complejo inka de Cortaderas, debe explorarse la posibilidad de que aquellos hayan sido grabados en tiempos inkaicos. 


\section{Motivos Presentes}

Como mencionamos anteriormente se han registrado en el sitio 250 representaciones (Figuras 2 y 3). Entre ellas, $164(65,6 \%)$ son figuras de animales. Hemos identificado 141 $(56,40 \%)$ como camélidos, uno $(0,40 \%)$ como un posible cánido y $22(8,80 \%)$ como zoomorfos no identificados ${ }^{2}$. Respecto del cánido (Bloque 24, Figura 4a), interpretamos que se trata de un perro, ya que esa forma de levantar y enrollar la cola es propia de este tipo de animales (Isabel Cornejo comunicación personal 2013). Sugerentemente, Mendoza y Valadez (2006) destacan que en el mundo andino primaron los perros de hocico largo y de orejas erguidas, como el cánido representado en los grabados del bloque 24 .

En cuanto a los antropomorfos, representan tan solo el 2,00\% $(n=5)$ de los grabados presentes en RDL1. Si bien nos ocuparemos con mayor

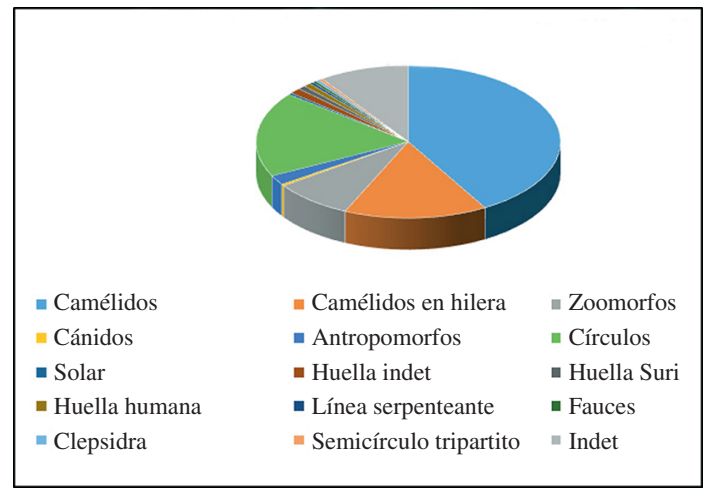

Figura 2. Frecuencia relativa de los motivos representados. Relative frequency of represented motifs.

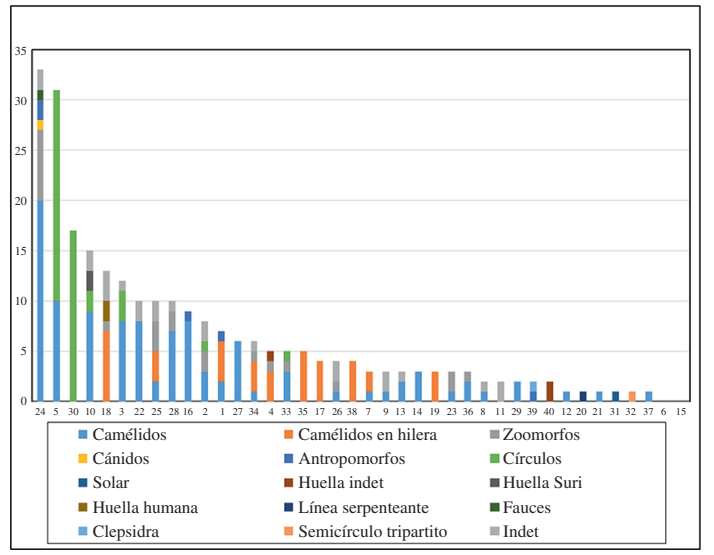

Figura 3. Presencia de motivos por bloque relevado. Presence of motifs per rock within the hillock. detalle más abajo, cuatro de los antropomorfos se encuentran en bloques junto a camélidos y tres de ellos en posiciones que se podrían relacionar con actividades pastoriles.

Otro motivo llamativo es un grabado circular (Figura $4 \mathrm{~b}$ ) desde donde nacen líneas en forma radial (por lo que se asemeja a un sol), ya que no se han registrado en la zona petroglifos con estas características. Tantaleán y Pinedo (2009) documentan un grabado similar en el valle del río Mala, en la costa central de Perú, el que es caracterizado por los autores como una porra estrellada y relacionado con la conquista inkaica de la zona.

A partir de los datos presentados en las Figuras 2 y 3 , puede observarse que entre los motivos figurativos representados, los zoomorfos se destacan como abrumadora mayoría, y que entre ellos sobresalen aquellos identificados como camélidos. Asimismo, del total de 40 bloques con grabados el $80 \%$ ( $\mathrm{n}=$ 32) cuentan con camélidos representados, siendo solo ocho los bloques sin este tipo de motivos.

Si bien no existe un único estilo o forma al momento de representar a este tipo de animales, una gran cantidad de ellos puede relacionarse con los que diversos autores han llamado esquemáticos y lineales; estos han sido hallados en una gran cantidad de sitios del noroeste argentino y norte de Chile y asignados a momentos tardíos dentro del período Intermedio Tardío, o bien, al período Inka (Aschero 2000; Berenguer et al. 2007; Gallardo y Vilches 1995; Martel 2010; Sepúlveda 2008; Vilches y Uribe 1999) (Figura 5). Dicho patrón se caracteriza por una esquematización geométrica rectilínea lineal, donde se representa al animal de perfil con solo una oreja y dos de sus patas. No obstante, y como mencionáramos antes, hay representaciones de camélidos que no se corresponden con ese tipo de calificación. Sin embargo, la dificultad en la definición de cronologías absolutas, la variabilidad existente en las asignaciones culturales y cronológicas, la ausencia de correlaciones estilísticas entre motivos rupestres y aquellos que se plasmaban en la cerámica local, y la ausencia de asociación regular entre manifestaciones rupestres y otros restos materiales, nos obliga a inferir la adscripción cultural de RDL1 de acuerdo con su inserción dentro de ciertas tendencias presentadas anteriormente para la zona de estudio. En particular, en lo que refiere a los motivos representados, la relación espacial que RDL1 mantiene con los sitios de la región, y la relación que mantiene respecto de características particulares del paisaje. 


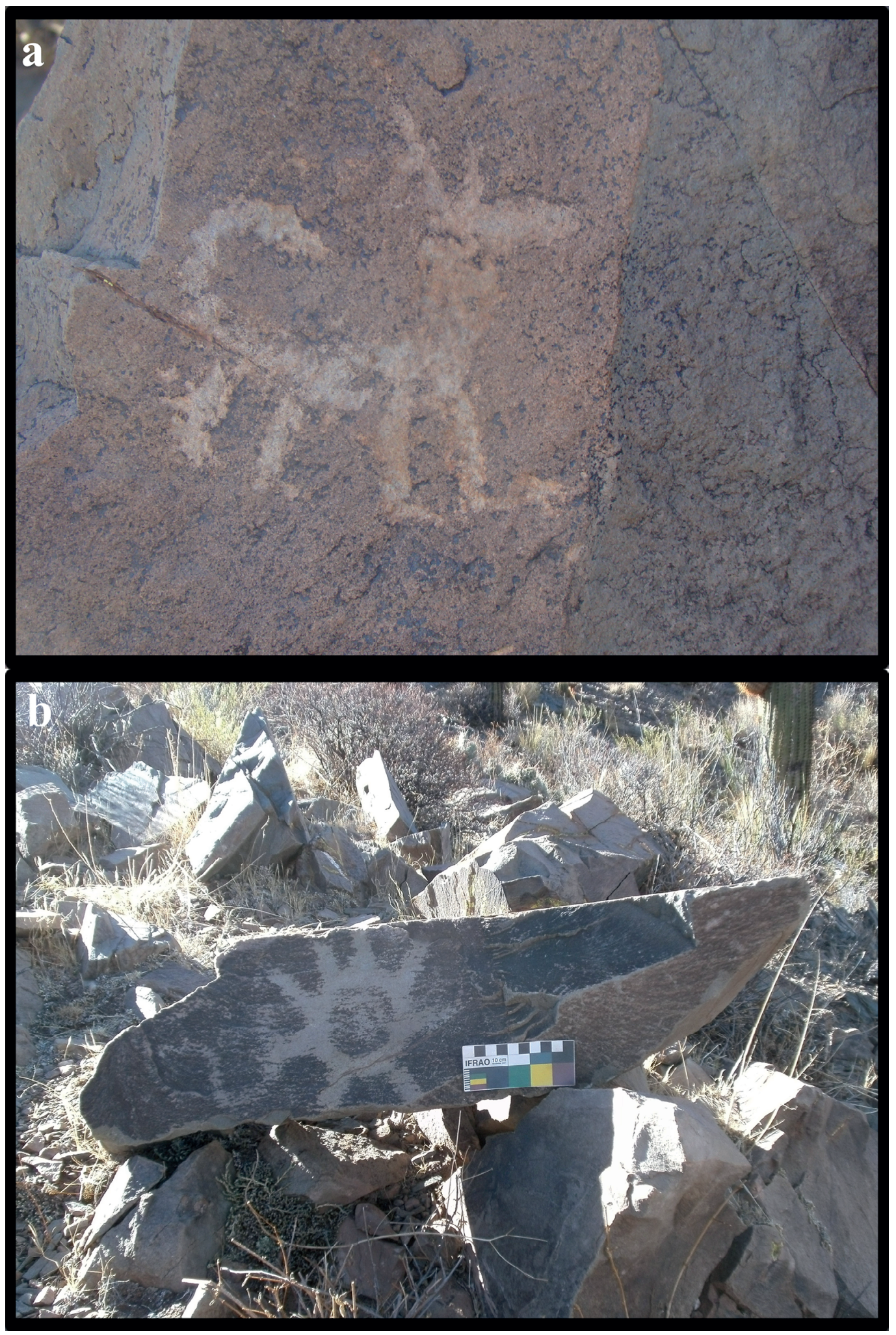

Figura 4. a. Representación figurativa de un perro. b. Motivo al que hemos denominado "solar". a. Figurative representation of a dog. $b$. "Solar" motif. 


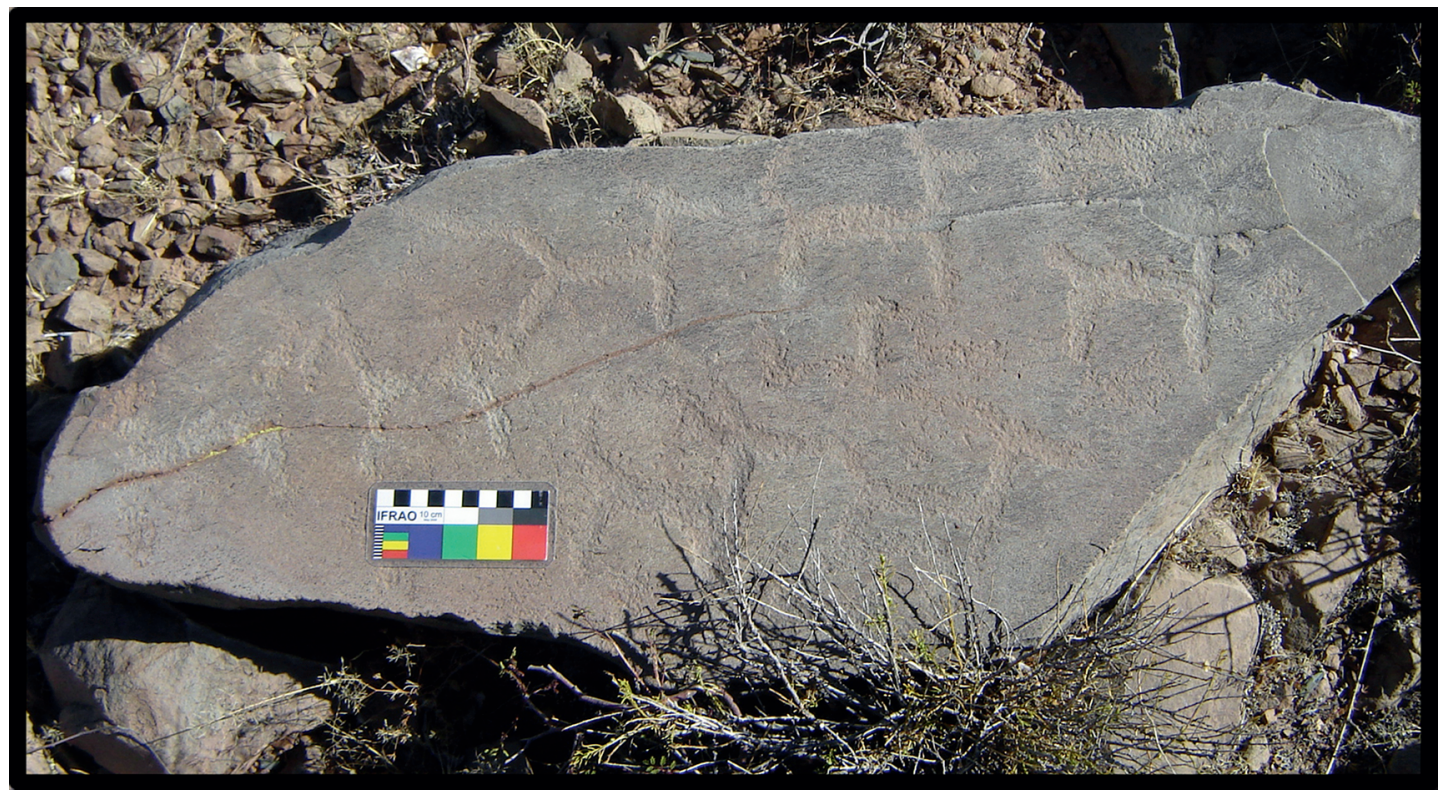

Figura 5. Camélidos esquemáticos.

Schematic camelids.

\section{RDL1 en Contexto Regional}

Mencionamos que ante la dificultad de fechar directamente esta clase de expresión cultural, solo nos queda remitirnos a su asociación con otras líneas de evidencia, interpretaciones que se han sugerido anteriormente, y referencias históricas complementarias.

A raíz de las prospecciones realizadas en el área mencionada en el 2013, podemos señalar al menos tres aspectos interrelacionados que parecen diferenciar a RDL1 y los afloramientos adyacentes de lo observado en otras concentraciones de petroglifos. El primero de ellos es compositivo, es decir, dependiente de las frecuencias relativas de los motivos presentes en los afloramientos rocosos del cerro. El segundo es representacional-figurativo, es decir, contempla a lo que los motivos aluden y la relación que existe entre ellos a escala de panel. El tercer aspecto es espacial, es decir, considera su relación física y visual con los sitios cercanos y aspectos particulares del paisaje.

\section{Aspecto compositivo}

En primer lugar, destacamos la superabundancia de representaciones de camélidos en RDL1 en relación con lo que fuera observado previamente en la región. Los trabajos de prospección en Los Cerrillos, una cadena de cerros bajos y afloramientos rocosos adyacentes de $8 \mathrm{~km}$ de longitud ubicada a unos $10 \mathrm{~km}$ de distancia de RDL1, permitieron identificar 1.331 figuras grabadas, distribuidas en 56 de estos cerros y afloramientos. La frecuencia relativa de camélidos presentes en aquellos cerros que presentan la mayor cantidad de $\operatorname{grabados}^{3}(>$ 100) oscila entre $13,74 \%(n=18)$ y $30,11 \%(n=$ 53) sobre 131 y 176 grabados respectivamente. Aun teniendo en cuenta que en ambos casos los camélidos son el motivo dominante, y que esta dominancia relativa se proyecta al total de los 1.331 grabados presentes en los Cerrillos $(27,12 \%, \mathrm{n}=361)$, la frecuencia relativa de camélidos representados en RDL1 $(56,40 \%, \mathrm{n}=141)$ lo destaca desde el punto de vista compositivo respecto de otros cerros relevados en la zona.

\section{Aspecto representacional}

Teniendo en cuenta que no deben conceptualizarse a las representaciones como reflejos de una práctica orientada hacia la creación de una narrativa histórica de carácter documental, consideramos que la dominancia relativa de camélidos en RDL1 debe enmarcarse en un contexto más amplio de significación que incluye relaciones anecdóticas 
con los antropomorfos representados. Para ello debemos hacer ciertas consideraciones previas.

Pese a que los antropomorfos (Figura 2) representan tan solo el 2,00\% $(n=5)$ de los grabados presentes en RDL1, la relación compositiva que mantienen con los camélidos resulta sugerente. Uno de ellos (Bloque 1, Figura 6a) se encuentra en un panel de 47 x $13 \mathrm{~cm}$ al frente de una hilera de cuatro camélidos, sosteniendo del cuello al primero de ellos. Si bien no se cubrió la totalidad de la superficie elegida para grabar, el tamaño estandarizado de los motivos representados y su disposición longitudinal sugieren una intencionalidad compositiva concreta. Es decir, remite a la asociación antropomorfos y camélidos a su existencia dentro del mismo plano de actuación y a una discrecionalidad narrativa dada por la inhabilitación de la cara grabada para albergar más motivos que los allí presentes. Podría sugerirse que las limitaciones corresponden exclusivamente a las dimensiones y forma general de la cara grabada. Sin embargo, 26,95\% ( $\mathrm{n}=38)$ de los camélidos está representado "en hilera" (Figura 2) y esto sucede con independencia de las dimensiones y extensión dominante de la cara grabada.

Otros dos antropomorfos (Bloque 24, Figura 6b) se encuentran junto a gran cantidad de camélidos. La particularidad de estas representaciones es que ambas se encuentran con sus brazos en alto, emulando un movimiento característico de la actividad pastoril. Cabe mencionar que uno de ellos, al igual que aquel presente en el bloque 1, parece sujetar por la cabeza a uno de los animales.

Un cuarto antropomorfo (Figura 6c), ubicado en el bloque 16, ha sido denominado, debido a sus características composicionales como mascariforme. Ocupa una posición central dentro de un panel en el que coexiste con ocho camélidos. Se trata de una figura que cuenta con una gran cabeza de forma trapezoidal con dos círculos a modo de ojos en su interior y dos pequeñas extremidades inferiores. Este es un motivo que no se ha encontrado representado en otros sitios de la región y que cuenta en este caso con particulares relaciones con el entorno circundante que serán discutidas más adelante.

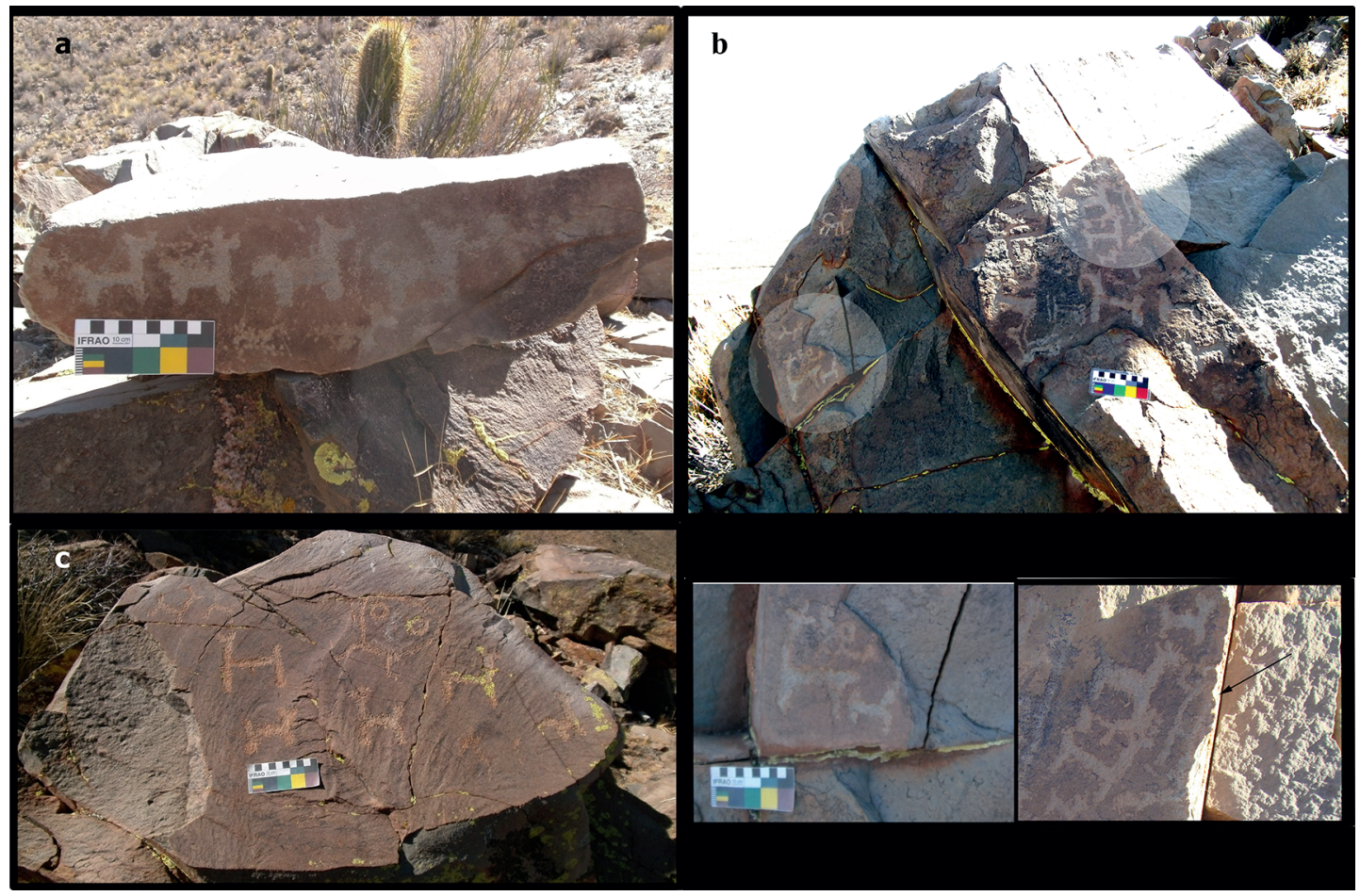

Figura 6. a. Camélidos integrando a un antropomorfo a la hilera. b. Antropomorfos representados en el bloque 24. c. Mascariforme rodeado de camélidos.

a. Camelids integrating one anthropomorphous figure to their alignment. b. Anthropomorphous figures in rock N ${ }^{\circ} 24$. c. "Masked" anthropomorphous surrounded by camelids. 
Destacamos que al menos tres de los antropomorfos representados se encuentran haciendo referencia a actividades relacionadas con el pastoreo de camélidos. La posición central del mascariforme en el panel del Bloque 16 (Figura 6c) resulta compositivamente sugerente, pero no nos aventuraremos a establecer una relación entre los motivos representados.

Si bien la asociación antropomorfos-camélidos en el mismo bloque o panel no es exclusiva de RDL1 y ha sido documentada en numerosas ocasiones en Los Cerrillos, la relación que proponen los grabados de RDL1 parece ser relativamente estrecha ${ }^{4}$. Sugerimos al respecto, que se investigue a futuro y en profundidad las características de aquellos camélidos que se encuentran acompañados de antropomorfos y aquellos que no, a fin de profundizar la asociación entre ambos motivos, ya que, si bien 26,95\% $(\mathrm{n}=38)$ de los camélidos representados está en hilera, solo cuatro de ellos $(f r=2,85 \%)$ integran un antropomorfo a la hilera.

\section{Aspecto espacial}

Se ha planteado previamente (Acuto et al. 2011) que, en el entramado espacial general del VCN, las zonas que presentan petroglifos se encontraban espacial y simbólicamente diferenciadas respecto de otros sitios (habitacionales, productivos, defensivos, etc.). Desde el punto de vista espacial por la notable baja frecuencia de rocas grabadas en sitios para otros propósitos, la notable ausencia de evidencia de restos arqueológicos en los sitios que concentran petroglifos, y la lejanía de los sitios y focos de ocupación. Como mencionamos anteriormente, los dos primeros contextos no son ajenos a RDL1. Para evaluar el tercer aspecto debemos ampliar la escala de análisis y retomar propuestas del patrón de asentamiento en esta porción del VCN.

\section{Relación con Sitios Inkas}

Acuto (1999) propone que esta zona del valle Calchaquí norte habría estado escasamente poblada antes de la conquista del Tawantinsuyu. Allí, los principales asentamientos inka (puros o bien con componentes inka y componentes locales) se distribuyen a lo largo del área del valle del río Potrero y en la zona que conecta el valle Calchaquí a la quebrada del Toro, de modo que se encuentran aislados de los focos centrales de ocupación local durante momentos previos al arribo inka, localizados hacia el sur. Es decir, que las dos modalidades privilegiadas para la ocupación del valle Calchaquí norte fueron: la construcción de asentamientos imperiales en la lejanía de los principales poblados locales, y la instalación de estructuras o complejos de estructuras en algunos de ellos. Se ha señalado que esto obedeció a una política de control y dominio que consistió en la creación de un nuevo nivel organizativo por arriba de las unidades políticas locales, lo que implicó la creación estratégica de un nuevo paisaje imperial material y simbólicamente significado a fin de "resocializar" y "re-educar" a las poblaciones locales. Este mecanismo de dominación necesitó de la participación de las poblaciones locales en nuevas espacialidades y materialidades (Acuto 1999; Acuto y Gifford 2007; Acuto et al. 2010; Acuto et al. 2012) que, a su vez, debió darse a dos escalas que se reforzaban mutuamente: de paisaje y de sitio.

De esta manera, se propuso que los inkas fueron los responsables del poblamiento de la zona con la construcción de grandes asentamientos como Potrero de Payogasta y el complejo de Cortaderas. En líneas generales, se trata de un asentamiento con cuatro sectores (superficie total: 26 ha) diferenciados tanto desde el punto de vista funcional como jerárquico (Acuto y Gifford 2007). Dos de ellos enteramente inkas (Cortaderas Bajo y Cortaderas Izquierda, SSalCac 65 y SSalCac 43 respectivamente), uno local (Cortaderas Alto, SSalCac 44) y uno predominantemente local con una única estructura inka de $529 \mathrm{~m}^{2}$ emplazada hacia el centro de este sector (Cortaderas Derecha, SSalCac 65D) (ver en detalle en Acuto y Gifford 2007). Como mencionamos anteriormente, RDL1 se encuentra a tan solo 1,4 y 1,6 km de distancia de los sitios Cortaderas Derecha y Cortaderas Bajo.

Cortaderas Bajo, con 4 ha de superficie, contiene numerosos conjuntos arquitectónicos o kanchas, y un imponente ushnu, edificado sobre una elevación natural. También cuenta con un espacio central con muro perimetral, que podría ser una plaza. Todos los edificios presentes en este sector de Cortaderas son típicamente inkaicos en su diseño de planta y técnicas constructivas.

Cortaderas Derecha, de 3 ha, se encuentra localizado a $1 \mathrm{~km}$ al sudoeste de Cortaderas Bajo, sobre la margen occidental del río Potrero. Presenta arquitectura local, que no fue construida durante el período de Desarrollos Regionales, sino que data 
de la época Inka y se corresponde con el abandono de Cortaderas Alto. Está compuesta principalmente por edificaciones de carácter residencial, con una considerable cantidad de desechos en superficie y numerosos edificios, basurales, tumbas y una estructura inka cuadrangular de $529 \mathrm{~m}^{2}$, que podría ser una plaza amurallada (Acuto et al. 2004:181).

Las excavaciones llevadas a cabo en Cortaderas Derecha, arrojaron evidencias que señalan que los residentes de este sector realizaban actividades orientadas a los intereses imperiales, permitiendo caracterizar al mismo como un enclave productivo. Se detectaron varios restos de producción metalúrgica que indicaron la existencia de una producción tecnológica bastante simple, que no requirió el uso de grandes hornos, sino que parece haber sido satisfecha empleando crisoles. Es decir, una tecnología fácilmente manejable a nivel doméstico (Acuto et al. 2004; Jacob 1999, 2011). No obstante, la presencia de moldes para la manufactura de lingotes de bronce estañífero, sugiere que la producción metalúrgica, a pesar de estar organizada a escala doméstica, estaba dirigida a satisfacer las demandas estatales.

Una de las actividades más importantes desarrolladas en Cortaderas Derecha, y que sin duda sobrepasó el nivel doméstico, fue la producción y el procesamiento de alimentos. Esto se sustenta en el relevamiento del $100 \%$ de la superficie del complejo Cortaderas, donde se detectaron tres morteros en Cortaderas Bajo, nueve morteros en Cortaderas Izquierda y 415 restos de morteros y conanas en Cortaderas Derecha. A esto debemos agregar que durante las excavaciones de Cortaderas Derecha se recuperó una gran cantidad de huesos de camélido, muchos de los cuales exhibían claras marcas de corte orientados a la obtención y procesamiento de carne. En este sentido, y si se considera que existen varias estructuras en este sector del sitio que pudieron haber sido usadas como corrales, puede inferirse que una de las tareas desarrolladas por los habitantes de Cortaderas Derecha fue el pastoreo y/o cría de camélidos (Acuto et al. 2004).

Al respecto, a la cercanía de RDL1 y la frecuencia relativa de camélidos representados y la relación que mantienen con los pocos antropomorfos grabados, debemos sumar que el posicionamiento de RDL1 (Figura 7) remite inevitablemente al abra que conecta esta zona de promontorios con el camino inka que atraviesa Cortaderas Bajo desembocando directamente en su plaza.

\section{Camélidos e Inkas}

Esta cercanía espacial entre los sitios inkas de Cortaderas y RDL1 cobra vigor al tener en cuenta la gran cantidad de camélidos allí representados y el valor de la llama en la cultura inkaica (Flores Ochoa et al. 1995; Murra 1964). Este tipo de animal ha sido de crucial importancia en gran cantidad de sociedades del mundo andino y las representaciones rupestres del mismo abundan desde tiempos tempranos. Sin embargo, los inkas han dejado testimonio de la particular consideración hacia los camélidos en general y las llamas en particular en el

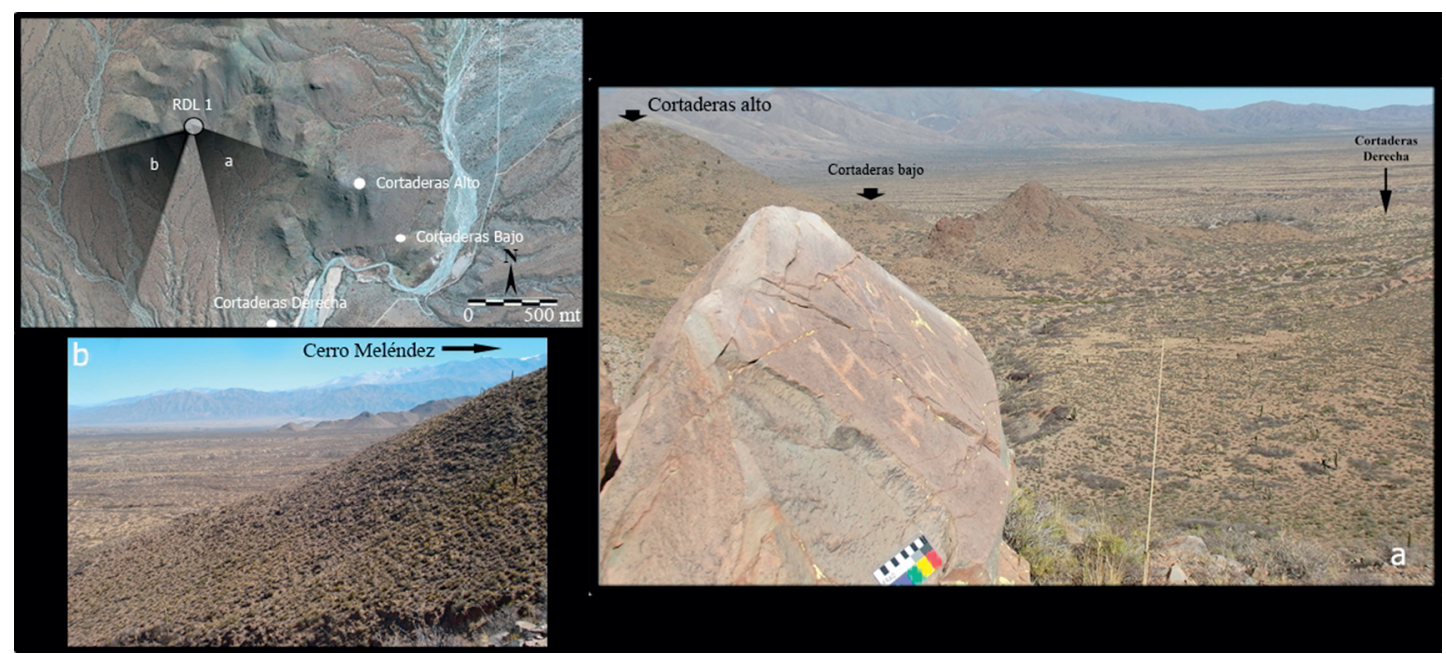

Figura 7. a. Vista hacia Cortaderas. b. Vista hacia el Cerro Meléndez.

a. View from RDL 1 towards Cortaderas. $b$. View from RDL 1 towards Cerro Meléndez. 
registro material (prácticas rituales y funerarias, arte rupestre y mobiliar, arquitectura, etc.). Estas, por su capacidad a la hora de transportar distintos tipos de materiales y por suministrar carne y fibras, crecieron en importancia con el aumento de la población y la expansión del Tawantinsuyu (Hostnig 2008). Hablamos entonces de un "estado imperial dominante, el que aparentemente daba un valor extraordinario a las llamas" (Echevarría y Valencia 2010:85). De este modo, puede decirse que la imagen del camélido fue un icono de la expansión inkaica; un signo poseedor de una gran carga simbólica (Sepúlveda 2004; Vilches 1999).

Tantaleán y Pinedo (2009:190) remarcan "la esquematización de escenas de recuas de camélidos (una actividad muy importante como forma de producción, distribución y consumo)" y la asociación con personajes que portan artefactos de indudable factura inkaica. Asimismo, destacan que dichos motivos se repiten en el lago Titicaca y en otras zonas del sur andino de modo que en este período, tanto en el noroeste argentino como en el norte chileno "el camélido se convierte en el "protagonista" de las representaciones rupestres" (Sepúlveda 2004:447).

Asimismo, las semejanzas formales entre este tipo de camélidos estilizados representados en estos y otros grabados y las figurinas metálicas halladas en diversos lugares del Tawantinsuyu, como por ejemplo las de las capacochas de los cerros Llullaillaco y Aconcagua (Ceruti 1997, 2003; Reinhard 1994; Schobinger et al. 1985) fueron notadas oportunamente por Gallardo y Vilches (1995:26). Estos autores destacan también el parecido entre estos grabados y las figuras de camélidos en los textiles inkas, a lo que debemos sumar posibles asociaciones con otras representaciones como las llamadas "llamas de Choquequirao" representadas en los andenes de este sitio en Cusco, Perú (Echevarría y Valencia 2010; Sepúlveda 2008), y a las llamas dibujadas en keros de madera inkas (Flores Ochoa et al. 1998; Lizárraga 2009).

Sepúlveda (2008:120) sostiene que "La simplificación de la forma de representación del camélido, y su geometrización se insertan perfectamente en las formas de representaciones incaicas". Se ha sugerido que la estandarización de motivos puede responder, entre otras cosas, a la facilidad que habilita a la hora de codificar, decodificar, y transmitir información (Fiore 2011), de modo que "el diseño camélido efectivamente actúa como una marca territorial en sitios nohabitacionales gracias a sus propiedades formales altamente estandarizadas y reconocibles a lo largo del imperio en diferentes dominios de la cultura material incaica" (Vilches y Uribe 1999:83).

\section{Relación entre Petroglifos y Montañas Nevadas}

Mencionamos anteriormente que en el registro de los petroglifos se tuvo en consideración la presencia o ausencia de asociaciones entre ellos y rasgos significativos del paisaje y el entorno inmediato, y que aquello nace de la necesidad de insertar las representaciones en contextos más amplios de significación.

Es conocida la importancia que las montañas, particularmente aquellas con sus cumbres cubiertas de nieve tienen y han tenido en la cosmología andina en general y en la inka en particular. Este es un tópico que ha sido ampliamente documentado a nivel etnográfico y arqueológico (Bastien 1978; Martínez 1983; Reinhard 1985) y que ha formado parte de algunos de nuestros trabajos anteriores (Acuto 2005; Acuto et al. 2011; Jacob et al. 2013; entre otros). Asimismo estos rasgos topográficos han sido identificados tempranamente (desde la misma llegada de los conquistadores españoles a los Andes) como entidades tutelares o Apus y/o pacarinas, el lugar de origen de las ancestros fundadores de las comunidades. En relación con esto Cristóbal de Albornoz escribía:

el prencipal género de guacas que antes que fuesen subjetos al ynga tenían, que llaman pacariscas, que quieren dezir creadoras de sus naturalezas. Son en diferentes formas y nombres conforme a las provincias: unos tenían piedras, otros fuentes y ríos, otros cuebas, otros animales y aves e otros géneros de arboles y de yervas y desta diferencia tratavan ser criados y descender de las dichas cosas... Hay entre estas guacas pacariscas muy muchas que reedificaron los ingas, dándoles muchos mitimas servicios que para este fin los mudava de unas provincias a otras. Dióles (el inga) muchos ganados y basos de oro y plata como fue en toda la cordillera que mira al mar, en todo lo que conquistó, en especial a cerros de nieve y bolcanes que miran a el mar y que salen los 
ríos que riegan muchas tierras (Albornoz 1967 [1568]:20).

En cuanto a la relación visual entre determinados puntos del paisaje y montañas consideradas sagradas, Herring (2010:94) destaca que en Cusco algunas construcciones de importancia se encontraban intencional y visualmente relacionadas con el cerro Huanacauri. Destaca un fragmento de la crónica de Bernabé Cobo (1964 [1653]) que menciona que en el Cusco inkaico barrancos y puntos bajos en la topografía de la ciudad que no contaban con una vista del Huanacauri se consideraban desfavorecidos.

Esta concepción acerca de las montañas y el paisaje no se limitaba a la ciudad de Cusco y sus alrededores sino que formo parte de todo el vasto territorio del Tawantinsuyu, siendo los cerros nevados partes fundamentales de la geografía sagrada provincial. Respecto del Nevado de Coropuna (Arequipa, Perú), Cieza de León comenta que:

se tuvo otro por estimado y frecuentado como ellos, y más, que había por nombre la Coropona, que es en la provincia de Condesuyo, en un cerro muy grande, cubierto a la continua de nieve que invierno y verano no se quita jamás. Y los reyes del Perú con los más principales de él visitaban este templo haciendo presente y ofrendas como a los ya dichos. Y tiénese por muy cierto que los dones y capacocha que a este templo se le hizo (Cieza de León 2005 [1553]:364).

Teniendo en cuenta estos conceptos hemos considerado que el cerro Meléndez, un cerro de 6.150 msm ubicado en el cordón montañoso del Nevado de Cachi, fue en tiempos prehispánicos una importante wak' $a$ a nivel regional, el Apu que dominaba el actual valle Calchaquí norte, la antigua provincia inkaica de Chicoana (Jacob y Leibowicz 2011, 2014). En relación con esto, cabe destacar que tanto el ushnu de Cortaderas Bajo como la única estructura inka presente en Cortaderas Derecha cuentan con una directa relación visual con el Meléndez, lo que nos lleva a pensar que en la construcción de estos sitios se vieron involucrados conceptos de orden cosmológico y ritual.

Si bien en la mayoría de los bloques analizados en RDL1 no pudieron observarse relaciones significativas entre los grabados y elementos de la naturaleza circundante, es interesante destacar el caso del Bloque 16 (Figura 7), aquel que cuenta con un antropomorfo mascariforme rodeado de ocho camélidos. El soporte de esta representación es un gran bloque de 1,59 $\mathrm{m}$ de altura máxima y el panel en donde se hallan los grabados mira hacia el oeste, donde se encuentran las cumbres cubiertas de nieve del Nevado de Cachi. El mascariforme en cuestión, ubicado a una altura de 1,45 m desde el piso, se encuentra directamente orientado $\left(259^{\circ}\right)$ hacia la cima del cerro Meléndez, donde se ha documentado la presencia de una plataforma y recintos de posible filiación inkaica (Vitry 2008).

Si bien esta figura es la única de las $250 \mathrm{del}$ sitio que posee estas características, pudimos comprobar a partir de exhaustivas prospecciones realizadas en la zona, que la relación entre grabados con representaciones antropomorfas y montañas nevadas no es exclusiva del mascariforme de RDL1.

A una distancia de poco más de $3 \mathrm{~km}$ de RDL1, en dirección noroeste y en la unión de dos cursos de agua temporarios, se encuentra un promontorio rocoso visible desde lo lejos. Cabe destacar que una de las primeras cosas que llamó nuestra atención fue su similitud con RDL1, respecto de la cantidad y tipo de rocas presentes. Sin embargo, al comenzar la prospección del promontorio pudo cotejarse que en su sección inferior, pese a contar con soportes pétreos idóneos, no existe ningún tipo de manifestación rupestre. $\mathrm{Al}$ ascender desde el lecho del río hacia la cima del promontorio, se localizó un petroglifo con dos personajes antropomorfos cuyas cabezas irradian líneas (Figura 8). Este grabado tiene características únicas para la zona, no habiéndose registrado con anterioridad un petroglifo de estas características. Sin embargo, el aspecto más destacable es que se encuentra en el primer punto, en el ascenso desde la base del promontorio, desde el cual se observan las cumbres del Nevado de Cachi (Figura 8). Más aún, ante la oferta de soportes, se ha elegido aquel que tiene una cara que apunta directamente hacia la cima nevada del cerro Libertador General San Martín de $6.380 \mathrm{msm}$ (orientación 259 ${ }^{\circ}$ ). Cabe mencionar que esta representación comparte el mismo afloramiento con una serie de camélidos que se encuentran en la cara este del mismo.

\section{Consideraciones Finales}

$\mathrm{El}$ arte rupestre, junto con la materialidad y la espacialidad que intervienen en la construcción de 


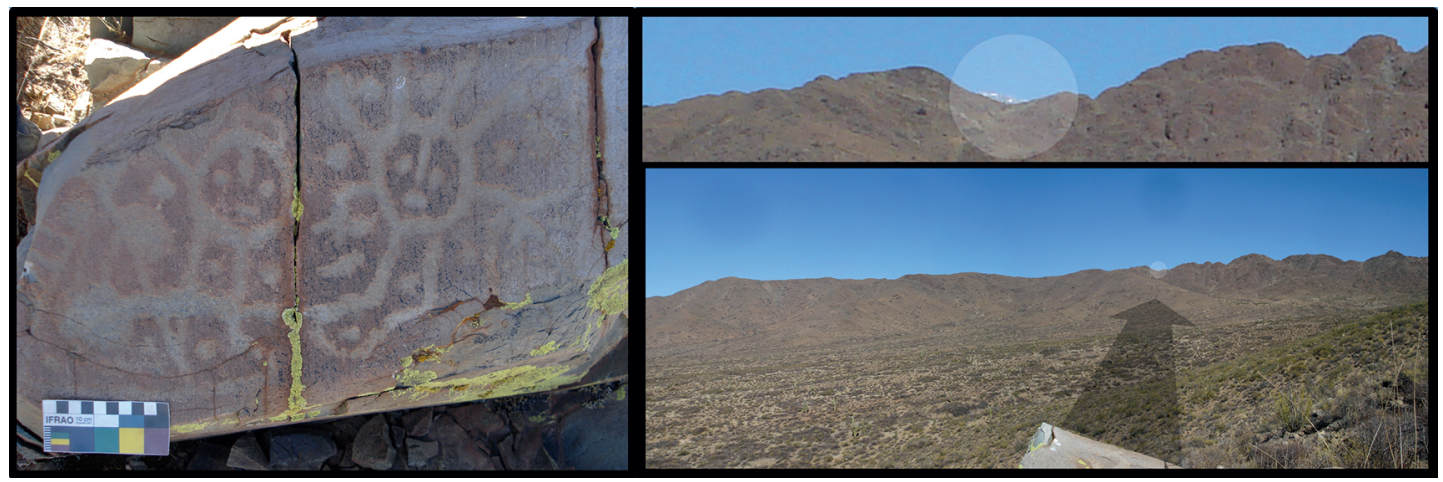

Figura 8. Izquierda: antropomorfos. Derecha: vista hacia las cumbres del Nevado de Cachi. Left: anthropomorphous figures. Right: view towards Nevado de Cachi's peaks.

nuevos paisajes sociales, ha sido utilizado por los inkas en sus estrategias de dominación y control de las sociedades integradas al Kollasuyu (Acuto 1999, 2005; Gallardo et al. 1995; Leibowicz 2007, 2012; Sepúlveda 2004, 2008; Troncoso 2004; Williams 2000/2004; entre muchos otros). En este contexto, las manifestaciones rupestres deben conceptualizarse teniendo en cuenta el entorno y las características de los espacios en que se produjeron, ya que conforman "un elemento de su constitución con valores referenciales e implicancias culturales" (Echevarría 2010:10). Esta conjunción de espacios y motivos representados articula "por un lado, la dinámica y valor de los diseños en su zona de origen, y por otro, las recepciones que acaecen en sus espacios de incorporación" (Troncoso 2011:223). Adicionalmente, la perdurabilidad inherente al soporte y la abundancia, estandarización, y repetición de motivos, proveen un dispositivo particularmente efectivo a la hora de producir y reproducir identidades, relaciones y prácticas asociadas (Fiore 2011). De este modo, las representaciones deben entonces integrarse a un contexto de significación que incluye a la vez que trasciende el entorno inmediato de acción, proyectando así su espacialidad, materialidad, y temporalidad más allá del evento concreto de producción.

Teniendo en cuenta el modo en que en el contexto inka los rasgos topográficos del paisaje constituyen un recurso simbólico de significación esencial en la creación y reproducción de estructuras de poder, tanto las relaciones espaciales con los vecinos sitios inkaicos como la sobrerrepresentación de camélidos en RDL1 en relación con otros sitios con petroglifos de la zona, nos llevan a sugerir que debe considerarse y corroborarse a futuro, que estos petroglifos fueron realizados en tiempos inkaicos.

Tomando en consideración que Cortaderas Derecha, decididamente un enclave productivo del Tawantinsuyu en la región, se domina claramente desde el promontorio rocoso en donde se encuentran los grabados, resulta sugerente la asociación entre la profusa cantidad de camélidos grabados y las posibles recuas cargadas de materiales que pudieron partir desde allí. Es decir, los aspectos compositivos y representacionales analizados en RDL1 nos remiten a estas recuas de camélidos que pudieron haber llevado tanto lingotes de metales como alimentos procesados a distintos asentamientos inkas, como ser las estructuras de almacenaje presentes en el sitio Los Graneros.

Respecto de la imposición de la cosmología inka sobre las poblaciones conquistadas en la región y la reorganización del paisaje mediante la apropiación y creación de espacios rituales (Acuto 1999, 2005; Jacob et al. 2013; Leibowicz 2012), la unicidad de ciertos motivos, la visibilidad dirigida por la ubicación topográfica y la orientación del panel seleccionado para plasmarlos nos sugieren una intención representacional (o intencionalidad y ya) que remite ciertos aspectos capitales de un paisaje "inkaizado". Tanto el mascariforme del bloque 16 de RDL1 como los antropomorfos de Petcort 6 (Figuras 7 y 8), se encuentran en directa relación visual con las cumbres del Nevado de Cachi, espacios cuya domesticación implicó el despliegue de toda la parafernalia ritual y simbólica inka. Debería explorarse y corroborarse la naturaleza de estos grabados atendiendo a un entramado más amplio de prácticas sociales vinculadas a la imposición 
del poder y la ideología imperial; actuando como parte de las múltiples estrategias de dominación desplegadas por el Tawantinsuyu en la región.

Agradecimientos: Esta investigación fue realizada con el apoyo del Programa de Becas Posdoctorales de la Universidad Nacional Autónoma de México, el Consejo Nacional de Investigaciones Científicas y Técnicas (Argentina) y financiada a partir de un subsidio otorgado por Wenner-Gren Foundation for Anthropological Research, International Collaborative Research Grant. Agradecemos a Ricardo Moyano y Guillermo Balda por su colaboración en los trabajos de campo y a Marisa Kergaravat por el apoyo logístico en la organización de las tareas de prospección. A la Escuela Rural ex $\mathrm{N}^{\circ} 799$ de Cortaderas, Salta. A los evaluadores por sus valiosas observaciones.

\section{Referencias Citadas}

Acuto, F.A. 1999. Paisaje y dominación: La constitución del espacio social en el Imperio Inka. En Sed Non Satiata. Teoría Social en la Arqueología Latinoamericana Contemporánea, editado por A. Zarankin y F.A. Acuto, pp. 33-76. Ediciones del Tridente, Buenos Aires.

Acuto, F.A. 2005. The materiality of Inka domination: Landscape, spectacle, memory, and ancestors. En Global Archaeology Theory: Contextual Voices and Contemporary Thoughts, editado por P.P. Funari, A. Zarankin y E. Stovel, pp. 211-235. Kluwer Academic/Plenum Publishers, New York.

Acuto, F.A., C. Aranda, C. Jacob, L. Luna y M. Sprovieri 2004. El impacto de la colonización Inka en la vida social de las comunidades del Valle Calchaquí Norte. Revista Andina 39:179-201.

Acuto, F.A., M. Smith y E. Gilardenghi 2011. Reenhebrando el pasado: hacia una epistemología de la materialidad. Boletín del Museo Chileno de Arte Precolombino 16:9-26.

Albornoz, C. de 1967 [1568]. Instrucción para descubrir todas las guacas del Pirú y sus camayos y haciendas. Journal de la Societe des Americanistes 56:17-39.

Aschero, C. 2000. Figuras humanas, camélidos y espacios en la interacción circumpuneña. En Arte en las Rocas. Arte Rupestre, Menhires y Piedras de Colores en la Argentina, editado por M.M. Podestá y M. de Hoyos, pp. 17-44. Sociedad Argentina de Antropología y Asociación Amigos del INAPL, Buenos Aires.

Bastien, J. 1978. Mountain of the Condor. Metaphor and Ritual in an Andean Ayllu. Waveland Press, Inc. Prospect Heights, Illinois.

Berenguer, J., G. Cabello y D. Artigas 2007. Tras la pista del Inca en petroglifos paravecinales al Qhapaqñan en el alto Loa, norte de Chile. Chungara Revista de Antropología Chilena 39:29-49.

Ceruti, M.C. 1997. Arqueología de Alta Montaña. Editorial MIBOR, Salta.

Ceruti, M.C. 2003. Elegidos de los dioses: Identidad y estatus en las victimas sacrificiales del Volcán Llullaillaco. Boletín de Arqueología PUCP 7:263-275.

Cieza de León, P. 2005 [1553]. Crónica del Perú y el Señorío de los Incas. Fundación Biblioteca Ayacucho, Caracas.

Cobo, B. 1964 [1653]. Historia del Nuevo Mundo. Atlas, Madrid.

Díaz, P.P. 1983. Arte rupestre en Valle Arriba. Estudios de Arqueología 3 y 4:9-25.
Echevarría Valencia, G.T. 2010. Las cuatro categorías técnico materiales del arte rupestre peruano. Red Patrimonio. Revista Digital de Estudios en Patrimonio Cultural (4 junio 2013) http://redcolmich.michoacan.gob.mx/index.php/red-patrimonio/ mision-y-vision/item/153-cuatro-categorias-arte-rupestre (30 julio 2013).

Echevarría Valencia, G.T. y Z. Valencia 2010. Las llamas de Choquequirao, arte imperial cusqueño en roca del siglo XV. Investigaciones Sociales 14:67-88.

Fiore, D. 2011. Materialidad visual y arqueología de la imagen. Perspectivas conceptuales y propuestas metodológicas desde el sur de Sudamérica. Boletín del Museo Chileno de Arte Precolombino 16:101-119.

Flores Ochoa, J., E. Kuon y R. Samanez 1998. Qeros. Arte Inka en Vasos Ceremoniales. Banco de Crédito del Perú, Lima.

Flores Ochoa, J., K. Mac Quarie y J. Portús 1995. Oro de los Andes: Las Llamas, Alpacas, Vicuñas y Guanacos de Sudamérica. Ediciones Jordi Blassi, Barcelona.

Gallardo, F., M. Uribe y P. Ayala 1995. Arquitectura inca y poder en el Pucara de Turi. Gaceta Arqueológica Andina 24:151-172.

Gallardo, F. y F. Vilches 1995. Notas acerca de los estilos de arte rupestre en el pukara de Turi (Norte de Chile). Boletín de la Sociedad Chilena de Arqueología 20:26-28.

Gilardenghi, E. 2010. Los nenes con los nenes, las nenas con las nenas: relaciones de género en el arte rupestre del sitio Los Cerrillos, Valle Calchaquí Norte (Pcia. de Salta, Argentina). La Zaranda de Ideas. Revista de Jóvenes Investigadores en Arqueología 4:71-89.

Herring, A. 2010. Shimmering foundation: The twelve-angled stone of Inca Cusco. Critical Inquiry 37:60-105.

Hostnig, R. 2008. Pinturas rupestres de posible afiliación Inca en el departamento del Cusco. http://rupestreweb.info.com/ incacusco.html (5 abril 2013).

Jacob, C. 1999. Combatiendo la corrosión: arqueometalurgia en el Valle Calchaquí Norte. Libro de Resúmenes del XII Congreso Nacional de Arqueología Argentina, pp. 164. Universidad Nacional de Córdoba, Córdoba.

Jacob, C. 2011. Metalurgia doméstica durante la presencia inka en el valle Calchaquí Norte, Salta-Argentina. Revista Haucaypata, Investigaciones Arqueológicas del Tahuantinsuyo 1:47-55. 
Jacob, C. e I. Leibowicz 2011. Montañas sagradas en los confines imperiales. Nevado de Cachi, Salta-Argentina. Revista Haucayapata. Investigaciones Arqueológicas del Tahuantinsuyo 2:71-90.

Jacob, C. e I. Leibowicz 2014. Ceremonias en la tormenta. Ritual Inka en el Nevado de Cachi. Estudios Antropología Historia Nueva Serie 2:27-48.

Jacob, C., I. Leibowicz, F. Acuto y R. Moyano 2013. Paisaje ritual y marcadores astronómicos en el sitio Uña Tambo, Nevados de Cachi, Salta, Argentina. Arqueología y Sociedad 26:291-302.

Jacob, C., R. Moyano, F. Acuto e I. Leibowicz 2011. Quilca del cielo: Valle Calchaquí, Salta, Argentina. Boletín APAR 3:348-350.

Lanza, M. 1996. Grabados rupestres en el Valle Calchaquí: avances y perspectivas. Chungara 28:223-239.

Leibowicz, I. 2007. Espacios de poder en La Huerta, Quebrada de Humahuaca. Estudios Atacameños, Arqueología y Antropología Surandinas 34:51-70.

Leibowicz, I. 2012. Ideología y espacio: conquista inka en la quebrada de Humahuaca, Jujuy, Argentina. Revista Chilena de Antropología 25:65-91.

Lizárraga, M. 2009. Las élites andinas coloniales y la materialización de sus memorias particulares en los "Queros de la transición" (vasos de madera del Siglo XVI). Boletín del Museo de Arte Precolombino 14:37-53.

Lorandi, A.M. 1966. El arte rupestre del noroeste argentino. Dédalo 11:15-172.

Martel, A. 2010. Arte Rupestre de Pastores y Caravaneros: Estudio Contextual de las Representaciones Rupestres durante el Período Agroalfarero Tardio (900 d.C.-1480 d.C.) en el Noroeste Argentino. Tesis para optar al grado de Doctor en Arqueología, Facultad de Filosofía y Letras, Universidad de Buenos Aires, Buenos Aires.

Martínez, G. 1983. Los dioses de los cerros en los Andes. Journal de la Societé des Americanistes 85:85-115.

Mendoza España, V. y R. Valadez Azúa 2006. El perro prehispánico andino: función y tipos a partir del análisis arqueozoológico. Anales de la XIX Reunión Anual de Etnología, pp. 31-38. Museo Nacional de Etnografía y Folklore (MUSEF), La Paz.
Murra, J. 1964. Rebaños y pastores en la economía del Tawantinsuyu. Revista Peruana de Cultura 2:76-101.

Reinhard, J. 1985. Sacred mountains: an ethnoarchaeological study of high Andean ruins. Mountain Research and Development 5:299-317.

Reinhard, J. 1994. Llullaillaco: investigación del yacimiento arqueológico más alto del mundo. Anales de Arqueología y Etnología 48 y 49:105-109.

Schobinger, J., M. Ampuero y E. Guercio 1985. Estatuillas del ajuar del fardo funerario hallado en el cerro Aconcagua. Relaciones de la Sociedad Argentina de Antropología 16:175-190.

Sepúlveda, M.A. 2004. Esquemas visuales y emplazamiento de las representaciones rupestres de camélidos del Loa Superior en tiempos incaicos. ¿Una nueva estrategia de incorporación de este territorio al Tawantinsuyu? Chungara Revista de Antropología Chilena 36:439-451.

Sepúlveda, M.A. 2008. Arte rupestre en tiempos incaicos: nuevos elementos para una vieja discusión. En Lenguajes Visuales de los Incas, editado por P. González y T. Bray, pp. 111-124. Archaeopress, Oxford.

Tantaleán, H. y O. Pinedo 2009. Las piedras en el camino: petroglifos y desplazamientos sociales durante la época Inca en el valle de Mala, costa central del Perú. En Crónicas sobre la Piedra. Arte Rupestre de las Américas, editado por M. Sepúlveda, L. Briones y J. Chacama, pp. 175-192. Ediciones de la Universidad de Tarapacá, Arica.

Troncoso, A. 2004. El arte de la dominación: Arte rupestre y paisaje durante el período incaico en la cuenca superior del río Aconcagua. Chungara Revista de Antropología Chilena 36:553-561.

Troncoso, A. 2011. Personajes fuera de lugar: antropomorfos tardíos en el arte rupestre del norte semiárido de Chile. Intersecciones en Antropología 12:221-230.

Vilches, F. 1999. Inka Rock Art?: Minor Arts, Major Meanings. Tesis para optar al grado de Master of Arts. University of Maryland, Maryland.

Vilches, F. y M. Uribe 1999. El dominio inca en las quebradas altas del Loa superior: un acercamiento al pensamiento político andino. Estudios Atacameños 18:73-87.

\section{Notas}

1 Sin embargo, esto no puede descartarse y se ha sugerido para otras zonas (Acuto et al. 2011).

2 Es importante tener en cuenta que estos zoomorfos serían casi en su totalidad camélidos, pero por no tener plena seguridad decidimos colocarlos en esta categoría.

3 A propósitos comparativos, no solo hemos tenido en cuenta aquellos que presentan la mayor cantidad de grabados, sino aquellos que presentan la mayor frecuencia relativa de camélidos.

4 Sin embargo, esto puede deberse simplemente al ratio camélidos-antropomorfos que exhibe RDL1 y no remitir indefectiblemente a una asociación intencionada, ya que la totalidad de antropomorfos representados coexiste, a escala de panel, con el 25\% ( $\mathrm{n}=36)$ de los camélidos representados. 
